\title{
O USO DE JOGOS E MATERIAL MANIPULÁVEL NO ENSINO DAS OPERAÇÕES COM NÚMEROS INTEIROS
}

\author{
THE USE OF GAMES AND MANIPULABLE MATERIAL IN THE TEACHING \\ OPERATIONS WITH INTEGERS
}

\section{EL USO DE JUEGOS Y MATERIALES MANIPULABLES EN LA ENSEÑANZA DE LAS OPERACIONES CON NÚMEROS ENTEROS}

\author{
Cristiane do Socorro dos Santos Nery* \\ José Romário Mendes Rodrigues \\ Karla Caroline Tavares ${ }^{*+*}$
}

\begin{abstract}
Resumo: Neste artigo, apresentamos uma pesquisa desenvolvida em uma escola pública no município de Macapá-AP e que objetivou analisar o desempenho de alunos do $7^{\circ}$ ano do Ensino Fundamental quando submetidos a uma sequência didática sobre operações com números inteiros, com o uso de jogos e material manipulável. Metodologicamente, trata-se de uma pesquisa quanti-qualitativa, com base na Teoria das Situações Didáticas. Os resultados indicam que a estrutura da sequência didática possibilitou saltos qualitativos na compreensão, socialização e autonomia para resolução das atividades. Concluímos que um conjunto de atividades devidamente estruturadas e planejadas com o uso de jogos e materiais manipuláveis contribui significativamente para o processo de ensino e aprendizagem dos alunos.
\end{abstract}

Palavras-chaves: Ensino e aprendizagem de matemática. Jogos e material manipulável. Operações com números inteiros.

\begin{abstract}
In this article we present a research developed in a public school located in Macapá-AP that aimed to analyze the performance of students of the 7th grade of Elementary School, when they are submitted to a didactic sequence on operations with integers, using games and manipulable material. Methodologically, it is a quantitative-qualitative research based on the Theory of Didactic Situations. The results indicate that the didactic sequence structure allowed qualitative leaps in comprehension, socialization and autonomy to resolve the activities. We conclude that a set of activities properly structured and planned with the use of games and manipulable materials contributes to the process of teaching and students learning.
\end{abstract}

Keywords: Teaching and learning of Mathematics. Games and manipulable material. Integers operations.

Resumen: En este artículo presentamos una pesquisa desarrollada en una escuela pública en el municipio de Macapá-AP que objetivó analizar el desempeño de alumnos del $7^{\circ}$ año de la Enseñanza Básica cuando sometidos a una secuencia didáctica sobre operaciones con números enteros, con el uso

\footnotetext{
* Universidade Federal do Amapá - UNIFAP. E-mail: csfsantos30@gmail.com

** Grupo de Estudos Pesquisas e Práticas em Educação na Amazônia Amapaense - GEPEA. E-mail: romario.mendes61@gmail.com

*** Grupo de Estudos Pesquisas e Práticas em Educação na Amazônia Amapaense - GEPEA. E-mail: karla.araujo@ outlook.com.br
} 
de juegos y materiales manipulables. Metodológicamente se trata de una pesquisa cuanti/cualitativa con base en la Teoría de las Situaciones Didácticas. Los resultados indican que la estructura de la secuencia didáctica posibilitó saltos cualitativos en la comprehensión, socialización y autonomía para resolución de las actividades. Concluimos que un conjunto de actividades debidamente estructuradas y planeadas con el uso de juegos y materiales manipulables contribuye significativamente para el proceso de enseñanza y aprendizaje de los alumnos.

Palabras-clave: Enseñanza y aprendizaje de matemáticas. Juegos y materiales manipulables. Operaciones con números enteros.

\section{Introdução}

A matemática é necessária em diversas atividades práticas que envolvem aspectos quantitativos da realidade humana, fazendo parte do nosso cotidiano direta ou indiretamente. Nos Parâmetros Curriculares Nacionais (PCN), é destacada a importância que a matemática assume na construção da cidadania de um indivíduo, pois devemos e necessitamos "saber calcular, medir, raciocinar, argumentar, tratar informações estatisticamente etc.” (BRASIL, 1998, p. 25).

Porém as dificuldades que envolvem a disciplina matemática são diversas. Quando se trata mais especificamente das operações com números inteiros, as dificuldades surgem pela ampliação dos números naturais com a inclusão dos números negativos que são essencialmente abstratos. Assim, a maneira como o professor desenvolve o conteúdo na sala de aula pode torná-lo cansativo, sem sentido e sem aplicabilidade.

Para Hillesheim (2013, p. 23), “o ensino dos números relativos no ensino fundamental enfrenta problemas que acabam repercutindo ao longo da vida escolar dos alunos". A autora destaca que as dificuldades geralmente encontradas pelos alunos estão relacionadas, entre outros fatores, à falta de sentido que as operações apresentam pela inclusão dos números negativos e sua abstração.
As operações com números inteiros é um conteúdo importante não só para o cotidiano do aluno, mas é a base para a resolução de equações mais complexas, permitindo ao aluno compreender conceitos mais avançados de matemática. Desta forma, é fundamental proporcionar aos alunos, sempre que possível, fazer relações, experiências e ter contato com o concreto.

Sabendo da importância deste conteúdo matemático e do uso necessário de novas metodologias para o ensino de matemática em sala de aula, foi elaborada uma sequência didática em conformidade com Pais (2011, p. 102), destacando que “é formada por um certo número de aulas planejadas e analisadas previamente com a finalidade de observar situações de aprendizagem”. Importa destacar que estas aulas normalmente fogem do caráter rotineiro da sala de aula, podendo ser denominadas de sessões, tendo em vista o caráter específico para pesquisa.

A sequência didática desenvolvida abrangeu a utilização de materiais manipuláveis para incentivar a descoberta do processo de resolução das operações, possibilitando o auxílio na compreensão de conceitos matemáticos e operações, jogos para sistematização e fixação do conteúdo.

Assim, nosso objetivo foi analisar o desempenho de alunos do $7^{\circ}$ ano do Ensino Fundamental quando submetidos a uma sequência didática com o uso de jogos e materiais manipuláveis relacionados ao conteúdo 
das operações com números inteiros, buscando favorecer o processo de ensino e aprendizagem das regras operacionais.

\section{O uso de jogos e materiais manipuláveis no ensino dos números inteiros}

O ensino dos números inteiros através de jogos e materiais manipuláveis são ferramentas metodológicas que possibilitam uma maneira diferenciada de aprender, e os alunos passam a ter a oportunidade de serem mais ativos no processo de ensino e aprendizagem, vivenciando mais intensamente a construção do saber. Os PCN destacam o uso de jogos como uma importante ferramenta na resolução de problemas, pois permite a apresentação de modo atrativo favorecendo também a criatividade na elaboração de estratégias e na busca de estratégias para atuar na atividade proposta.

As habilidades e competências provenientes do uso de jogos contribuem para a qualidade do ensino e aprendizagem de matemática na sala de aula, visto que alguns conteúdos matemáticos são considerados difíceis e cansativos pelos alunos. Além disso, conforme os estudos de Salgado (2011), Bordin (2011) e Liell (2012), os jogos proporcionam momentos de interação, cooperação, assimilação das regras sem decorar, o que leva os alunos a se tornaram mais ativos e partícipes da construção do conhecimento.

Assim, por meio do jogo podemos reconhecer os saberes que os alunos estão aplicando no momento da interação com os objetos e temos a oportunidade de vincular o conteúdo que deve ser ensinado à realidade do educando. Na educação matemática, ao escolher o jogo que será utilizado como recurso pedagógico no processo de ensinar e aprender, deve-se ter em mente a adequação a ser feita ao conteúdo que será desenvolvido.

Os jogos, quando utilizados como meio metodológico para o ensino, possibilitam a construção do conhecimento significativo em contraste ao conhecimento mecanicista do método tradicional de ensino e permitem ao indivíduo deixar de lado o papel de ser um mero assimilador de conhecimentos transmitidos. Coll destaca:

Mediante a realização de aprendizagens significativas, o aluno constrói, modifica, diversifica e coordena os seus esquemas, estabelecendo, deste modo, redes de significados que enriquecem o seu conhecimento do mundo físico e social e potenciam o seu crescimento pessoal. (COLL, 1994, p.137)

Por sua vez, Grando (1995) enfatiza que o jogo propicia um ambiente favorável à motivação da criança em relação à aprendizagem, não apenas pelos objetos que o constituem, mas também pelos desafios que as regras impõem em uma situação imaginária. Esta situação imaginária pode ser considerada um meio para o desenvolvimento do pensamento abstrato, e, quando se trata do ensino das operações com números inteiros, o desenvolvimento do abstrato torna-se essencial para uma melhor compreensão e fixação do conteúdo em questão.

Além do uso de jogos e sua importância para o processo de ensino e aprendizagem, destacamos também o uso de materiais manipuláveis em sala de aula. Pestalozzi, no século XIX, defendia o uso dos materiais manipuláveis como elemento fundamental para o ensino. Mais tarde, em meados do século XX, Montessori e Decroly desenvolveram os primeiros materiais manipulativos utilizados no ensino de matemática, como por exemplo, o material dourado.

Assim, o material manipulável não deve ser visto apenas como um "acessório", sendo necessários em determinados momentos e inadequados em outros. É importante 
que o aluno, após o manuseio do material, sinta-se confiante para não fazer mais uso dele e, então, abrir mão desse suporte para trabalhar sem esse auxílio. Nesse sentido, Nacarato (2005, p.4) destaca que "um uso inadequado ou pouco exploratório de qualquer material manipulável pouco ou nada contribuirá para a aprendizagem matemática. O problema não está na utilização desses materiais, mas na maneira como utilizá-los”.

Para Castelnuovo (apud FIORENTINI; MIORIM, 1990, p. 4), a utilização de materiais manipulativos tem por finalidade exercitar as faculdades analíticas e sintéticas das crianças. Sintéticas no que se refere à construção de determinado conceito partindo sempre do concreto; analíticas, em que o aluno tem a compreensão dos elementos que constituem o objeto como um todo.

Quando os materiais manipulativos são utilizados como recursos metodológicos é importante deixar que os alunos tenham contato com o material, que criem hipóteses, analisem e tirem suas próprias conclusões. A utilização de materiais manipuláveis pode favorecer o salto cognitivo no estágio de desenvolvimento do aluno, abstraindo conceitos e adquirindo autonomia para resolver problemas. Portanto, o uso de jogos e materiais manipuláveis em sala de aula são importantes para a compreensão dos conteúdos pelos alunos. Pommer destaca que:

[...] a introdução de situações contextualizadas, jogos e materiais manipuláveis, associadas ao uso da linguagem matemática, expressas em diversas possibilidades, viabilizam um trabalho didático que permite superar obstáculos epistemológicos, ao esclarecer as escolhas realizadas ao longo do percurso de construção do conhecimento matemático envolvendo os números inteiros. (POMMER, 2010, p. 4)
Dessa forma, valoriza-se a manipulação, a experimentação e a ação sobre os objetos a serem aprendidos, o uso de jogos, materiais manipuláveis e situações que potencializam o lúdico e as experiências como atividades centrais.

\section{Aspectos metodológicos}

A presente pesquisa foi desenvolvida em uma turma do $7^{\circ}$ ano de uma escola pública do município de Macapá-AP no ano de 2015, envolvendo 12 alunos. A natureza de nossa pesquisa foi de cunho quanti-qualitativa. O uso das abordagens é destacado por Minayo (1994), pois as relações entre abordagens qualitativas e quantitativas demonstram que: a) as duas metodologias não são incompatíveis e podem ser integradas num mesmo projeto; b) que uma pesquisa quantitativa pode conduzir o investigador à escolha de um problema particular a ser analisado em toda sua complexidade, através de métodos e técnicas qualitativas e vice-versa; c) que a investigação qualitativa é a que melhor se coaduna ao reconhecimento de situações particulares, grupos específicos e universos simbólicos.

Buscando atingir nosso objetivo e partindo do conceito de que “a pesquisa é um procedimento formal, com método do pensamento reflexivo, que requer um tratamento científico, e se constitui para conhecer a realidade ou descobrir verdades parciais” (MARCONI; LAKATOS, 1991, p.15), o desenvolvimento de nossa pesquisa deu-se a partir de uma sequência didática que abrange a utilização do material manipulável (quadrados coloridos) e jogos (jogo financeiro, dama da multiplicação e divisão, dominó das operações) para sistematização e fixação do conteúdo.

O processo de coleta de informações na realização de uma sequência didática é 
essencial para que ocorra de fato a aprendizagem significativa. Nesse sentido, fizemos uso de testes, diário de campo e registros em áudio e fotográfico para que pudéssemos atender as dificuldades dos alunos que poderiam surgir durante a intervenção.

A sequência didática foi desenvolvida em cinco sessões de ensino e teve como aporte teórico a Teoria das Situações Didáticas de Brousseau. Segundo Brousseau:

Uma situação didática é um conjunto de relações estabelecidas explicitamente e ou implicitamente entre um aluno ou um grupo de alunos, compreendendo eventualmente instrumentos e objetos, e um sistema educativo (o professor) com a finalidade de possibilitar a estes alunos um saber constituído ou em vias de constituição [...]. (BROUSSEAU, 1986, p. 8)

Na primeira e última sessão, ocorreu a aplicação do pré-teste e pós-teste respectivamente, com objetivo de produzir dados que permitissem realizar comparações entre o desempenho dos discentes na resolução de questões de adição, subtração, multiplicação, divisão, além de propriedades aritméticas dos números inteiros, antes e depois do desenvolvimento da sequência didática.

\section{Experimentação: aplicação dos quadrados coloridos, jogo financeiro, dama da multiplicação e divisão, dominó das operações no ensino dos números inteiros}

Após a primeira sessão (pré-teste), apresentamos aos alunos o material manipulável intitulado de "Quadrados Coloridos", nas cores azul e laranja e que representavam, respectivamente, uma unidade positiva e uma unidade negativa.
Figura 01: Material manipulável "Quadrados Coloridos"

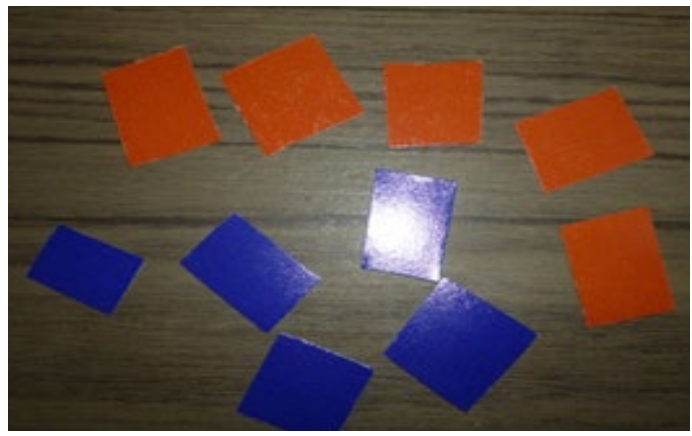

Fonte: Pesquisa de campo/2015.

Nas operações de adição, um quadrado laranja anula um quadrado azul quando adicionados. Exemplo:

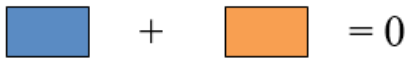

Nas operações de subtração, utilizou-se o conceito de oposto para se obter o resultado correto, incluindo o devido sinal. Exemplo:

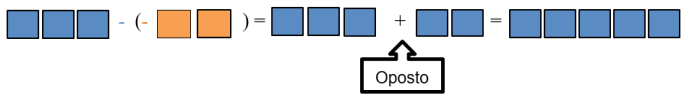

Na multiplicação, se os fatores fossem positivos, os alunos utilizariam apenas os quadrados da cor azul para chegar ao resultado, pois eles indicam os números positivos, e repetiriam o segundo fator quantas vezes o primeiro fator determinasse. Se os dois fatores fossem negativos, se utilizaria o conceito de oposto para obter o resultado positivo do produto e o quadrado azul no material, ou seja, o sinal negativo, quando acompanhar o primeiro fator e o segundo fator, indica que se devesse utilizar quadrados das cores azuis no resultado.

$$
\text { Exemplo: }(-4) \times(-1)=+4
$$

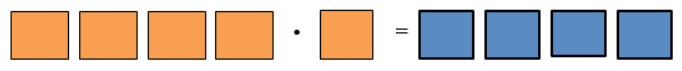


Quando um dos fatores é positivo e outro é negativo, como, por exemplo, 3 x (-2), o número positivo representará a quantidade de vezes que o número negativo deverá ser repetido, será a soma de parcelas iguais.

Para a resolução das operações de divisão com o material, os alunos deveriam seguir basicamente as mesmas instruções das operações de multiplicação, pois as regras de sinais são iguais. Assim, os alunos resolveriam da seguinte forma: quando o dividendo é positivo e o divisor é negativo, como no exemplo -6 : 2 , tem-se dois grupos de 3 quadrados laranjas, portanto $-6: 2=-3$.

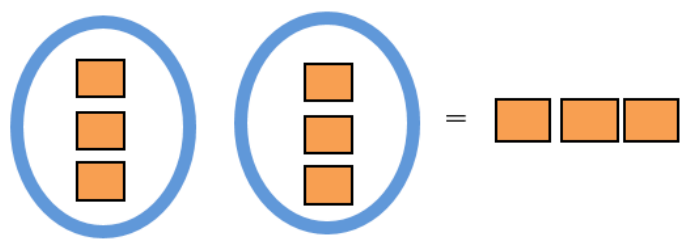

Quando o dividendo e o divisor são negativos, utiliza-se novamente o conceito de oposto para se obterem quadrados azuis no material, que representam os números positivos. Nas operações com números positivos, os alunos fariam as representações nos quadrados azuis e obteriam o resultado positivo.

Após a apresentação do material, ainda na segunda sessão desenvolveu-se a atividade “Adição e subtração com sinais iguais" e a atividade "Adição e subtração com sinais diferentes”, cujo objetivo era trabalhar com as regras de sinais das operações de adição e subtração de números inteiros, buscando a percepção dos alunos sobre as regularidades nas regras de sinais com auxílio dos “Quadrados Coloridos”.

Após a realização das atividades envolvendo as operações de adição e subtração de números inteiros, com o objetivo de sistematizar e possibilitar a compreensão das regras operacionais envolvendo essas operações, desenvolveu-se o jogo denominado "Jogo financeiro”.

O "Jogo Financeiro" foi realizado em equipes de 5 alunos e é formado por 70 fichas azuis que representam a situação de crédito e 70 fichas laranjas que representam a situação de dívida. Além disso, contém 30 fichas com instruções para o devido andamento do jogo. Cada equipe determinou quem seria responsável por ser o banqueiro, sendo os outros quatros membros designados para realizar as “transações financeiras”.

Ao iniciar o jogo, o primeiro jogador deveria comprar uma ficha do centro da mesa e seguir a instrução nela escrita. Caso o jogador não tenha a quantidade necessária de fichas para efetuar a transação solicitada no cartão retirado, deverá recorrer ao banqueiro. $\mathrm{O}$ jogo termina quando um jogador retirar a ficha com a instrução "Fim de Jogo". Depois disto, os jogadores verificaram os seus respectivos balanços financeiros, e vence o jogo aquele que tem mais crédito (fichas azuis não anuladas por fichas laranja).

Na terceira sessão tivemos a atividade "Multiplicação e divisão com sinais iguais" e a atividade "Multiplicação e divisão com sinais diferentes”, sendo resolvidas com auxílio do material manipulável. Estas atividades tinham como objetivo trabalhar as regras da multiplicação e divisão com números inteiros e, buscando sistematizar essas regras operacionais, foi realizado o Jogo "Dama da Multiplicação e Divisão”.

O Jogo "Dama da Multiplicação e Divisão” era composto por um tabuleiro com 24 peças numeradas de -12 a 12 , sendo necessários quatro participantes, formando duas duplas. O jogador escolhido para iniciar moveria apenas uma peça por vez, com o objetivo de eliminar uma das peças do adversário, e as peças só poderiam ser movidas na diagonal. 
Quando a peça do adversário era eliminada, a dupla realizava a multiplicação ou a divisão (em uma tabela), entre a peça eliminada do adversário e a sua peça que causou a eliminação, observando os números positivos e negativos. O jogo era finalizado quando uma dupla eliminava todas as peças do adversário.

Na penúltima sessão, foi desenvolvido o jogo “Dominó das operações” com o objetivo de trabalhar a fixação das regras de sinais das quatro operações envolvendo os números inteiros desenvolvidas nas sessões anteriores.

O Jogo “Dominó das Operações”, semelhante ao jogo de dominó tradicional, tem quatro participantes, que formam duas duplas, devendo sentar em posições alternadas. As peças são postas na mesa, e cada jogador pega 7 para jogar. Quando a primeira peça é jogada, os demais jogadores tentam encaixar outra em uma das extremidades da peça que já está sobre a mesa, sendo um por vez. As peças só encaixam se combinarem a operação com o devido resultado ou se as operações corresponderem ao mesmo resultado. A partida pode terminar em duas circunstâncias: quando um jogador conseguir bater o jogo (jogar todas suas peças), ou quando o jogo ficar trancado (ninguém possui peças que correspondem a uma das extremidades).

\section{Análises e resultados}

Na Teoria das Situações Didáticas, Brousseau (2008) determina que uma situação é um modelo de interação de um sujeito com um meio determinado, em que um dispositivo deve ser colocado em ação para que uma pessoa ensine um conhecimento e controle a sua aquisição. Este dispositivo é um meio material que pode ser peças de um jogo, um problema e regras de interações do aprendiz com aquele dispositivo.
As situações devem ser realizadas de maneira a provocar o aparecimento dos conhecimentos que os alunos trazem; assim, a socialização dos alunos durante o desenvolvimento das atividades através do material manipulável possibilitou que eles interagissem sobre as regras de modo mais produtivo e dinâmico. No momento de interação, os alunos elaboraram estratégias, desenvolvendo uma situação didática de ação, de acordo com a tipologia das situações didáticas estabelecida por Brousseau (1986), em que o aluno reflete e realiza tentativas ao eleger um procedimento de resolução dentro de um esquema de adaptação.

Iniciamos a análise pela segunda sessão, tendo em vista que apresentaremos o préteste (primeira sessão) e o pós-teste (última sessão) conjuntamente no final da análise. A segunda sessão contou com duas atividades e um jogo identificados como "Adição e subtração com sinais iguais”, “Adição e subtração com sinais diferentes” e “Jogo financeiro”. Na resolução da atividade “Adição e subtração com sinais iguais”, os alunos não apresentaram grandes dificuldades na resolução das operações, e o índice de acertos superou as expectativas, tendo um total de 95\% de respostas corretas. Consideramos que a utilização do material manipulável e a postura dos professores pesquisadores enquanto mediadores do processo de ensino e aprendizagem contribuíram consideravelmente para o alto índice de acertos das operações.

Na resolução da atividade "Adição e subtração com sinais diferentes”, foi verificado que os alunos apresentaram dificuldades na elaboração de estratégias com os quadrados coloridos para resolução de algumas questões, evidenciando um conhecimento não formulado matematicamente. 
Quadro 01: Respostas dos alunos do $7^{\circ}$ ano da atividade de adição e subtração com sinais diferentes

\begin{tabular}{|l|l|l|l|l|l|l|}
\hline & \multicolumn{7}{|c|}{ RESPOSTAS DOS ALUNOS } \\
\hline QUESTÕES & ALUNO I & ALUNO N & ALUNO O & ALUNO S & ALUNO T & ERROS (\%) \\
\hline 4$)+7-5=$ & Não informa & +4 & Não informa & -2 & Não informa & $60 \%$ \\
\hline 5$)+9-12=$ & -4 & Não informa & +4 & Não informa & +4 & $60 \%$ \\
\hline 10$)-12+3=$ & -15 & Não informa & -15 & Não informa & -6 & $60 \%$ \\
\hline
\end{tabular}

Fonte: Pesquisa de campo/2015

Nas questões 4 e 5, o erro principal dos alunos foi a falta de atenção, pois não percebiam o sinal positivo na frente da operação, o que consequentemente levou à realização equivocada da operação sem dar o sinal correto. É importante destacar que todos os alunos participantes desta atividade acertaram pelo menos uma das duas operações, uns acertaram somente a $4^{\mathrm{a}}$ questão, outros somente a $5^{\mathrm{a}}$, o que comprova a falta de atenção no momento da resolução, visto que a estrutura das operações era a mesma.

Na questão de número 10, o erro estava novamente na falta de atenção ao não perceberem o sinal na frente da operação, que desta vez era o negativo, o que gerou a soma da operação. Nesta operação, 60\% dos alunos erraram e, do total de erros, $66,6 \%$ dos alunos erraram desta forma.

A socialização dos resultados foi o momento oportuno para confrontar as respostas dos alunos, evidenciar os equívocos e acertos para em seguida trabalharmos as propriedades do jogo de sinais nas operações de adição e subtração com números inteiros. É importante frisar a importância da institucionalização do saber, que diz respeito à intervenção do professor no processo de aprendizagem mediado por jogos e atividades estruturadas.

Sobre a institucionalização, Brousseau (1996, p. 71) alerta que é etapa indispensável da aprendizagem e é constitutiva do saber em relação aos conhecimentos, é um trabalho cultural e histórico que compete ao professor estabelecer ou concretizar naturalmente determinadas situações.

Para o desenvolvimento dos jogos, foi necessário que os alunos se organizassem em grupos. Kamii e De Vries (1991 apud ALVES, 2012) ressaltam, com base em Piaget, que a interação social entre os colegas propiciada pelo grupo pode levar à construção de lógicas, valores sociais e morais, e estimula a capacidade de cooperação.

No desenvolvimento do "Jogo Financeiro”, que também fazia parte da quarta sessão, constatou-se que a socialização da estratégia criada pelos alunos para resolução das “transações financeiras” contribuiu positivamente para o desenvolvimento do jogo, pois cada um cooperava com o outro em relação ao que deveria ser feito. Neste sentido, o PCN disserta que o trabalho coletivo supõe uma série de aprendizagens, tais como:

- Perceber que além de buscar a solução para uma situação proposta devem cooperar para resolvê-las e chegar a um consenso; - Saber explicar o próprio pensamento e tentar compreender o pensamento do outro; discutir as dúvidas, assumir que as soluções dos outros fazem sentido e persistir na tentativa de construir suas próprias ideias; - Incorporar soluções alternativas, reestruturar e ampliar a compreensão acerca dos conceitos envolvidos nas situações e, desse modo, aprender. (BRASIL, 1997)

A interação proporcionada pelo jogo e a postura dos professores pesquisadores 
enquanto mediadores do processo de aprendizagem foram de suma importância para fixação das regras sistematizadas nas sessões anteriores. O esforço de cada um para realizar a operação mentalmente e chegar a resultados corretos, transferindo para o jogo o aprendizado adquirido, indagando, refletindo, elaborando estratégias, compreendendo e não apenas decorando as regras de sinais inerentes as operações assim como a motivação e o desafio contido no ato de jogar levaram os alunos à assimilação do que foi proposto.

Na terceira sessão tivemos a atividade "Multiplicação e divisão com sinais iguais" e a atividade "Multiplicação e divisão com sinais diferentes”, que foram resolvidas com auxílio do material manipulável, e o Jogo “Dama da Multiplicação e Divisão”. Na atividade "Multiplicação e divisão com sinais iguais" constatamos que as dificuldades estavam diretamente relacionadas ao sinal dos números e não da operação em si. Verificamos que alguns alunos ainda tinham a dificuldade de resolver as operações quando os sinais dos números estavam implícitos e, como consequência, não sabiam qual cor de quadrado do material manipulável utilizar.

Inicialmente, nas questões 1, 2, 3, 4, e 5, que tratavam sobre a multiplicação de sinais iguais positivos, todos os alunos acertaram o sinal do resultado das operações. A exceção foi as respostas de uma aluna nas questões 3 e 5, nas quais ela colocou o sinal de positivo no resultado, e, portanto, o resultado da operação não foi o correto.

Quadro 02: Respostas dos alunos do $7^{\circ}$ ano da atividade de multiplicação com sinais iguais e positivos

\begin{tabular}{|l|c|c|c|c|c|c|}
\hline & \multicolumn{7}{|c|}{ RESPOSTAS DOS ALUNOS } \\
\hline QUESTÕES & ALUNO A & ALUNO B & ALUNO C & ALUNO D & ALUNO E & ACERTOS (\%) \\
\hline 1) $3 \times 2$ & +6 & +6 & +6 & +6 & +6 & $100 \%$ \\
\hline 2) (+4) x (+7) & +28 & +28 & +28 & +28 & +28 & $100 \%$ \\
\hline 3) 7 × 6 & +42 & +30 & +42 & +42 & +42 & $80 \%$ \\
\hline 4) (+10) x (+3) & +30 & +30 & +30 & +30 & +30 & $100 \%$ \\
\hline 5) $11 \times 2$ & +22 & +26 & +22 & +22 & +22 & $80 \%$ \\
\hline
\end{tabular}

Fonte: Pesquisa de campo/2015.

O resultado obtido na resolução das questões de multiplicação com sinais iguais positivos evidenciou que quase a totalidade de alunos domina a multiplicação de números naturais.

Já nas operações de multiplicação com sinais iguais negativos, nossa hipótese foi confirmada: os alunos apresentaram dificuldade no momento de definir se o resultado era positivo ou negativo. A maioria dos alunos sabia o resultado da operação, mas acabavam por colocar o sinal (-) no resultado ao invés de trabalhar o oposto do segundo fator, colocando assim o sinal (+).

Nas questões de divisão com números inteiros de sinais iguais positivos, os alunos não demonstraram dificuldade para resolver as operações que envolviam apenas números naturais positivos. Assim como na resolução das questões de multiplicação, muitos alunos perceberam que o resultado dava sempre positivo, antes mesmo de terminar de resolver as questões. Todos os alunos chegaram ao resultado correto. 
Quadro 03: Respostas dos alunos do $7^{\circ}$ ano da atividade de divisão com sinais iguais e positivos

\begin{tabular}{|l|c|c|c|c|c|c|}
\hline & \multicolumn{7}{|c|}{ RESPOSTAS DOS ALUNOS } \\
\hline QUESTÕES & ALUNO I & ALUNO N & ALUNO O & ALUNO S & ALUNO T & ACERTOS (\%) \\
\hline 11$) 6: 3$ & +2 & +2 & +2 & +2 & +2 & $100 \%$ \\
\hline 12$) 16: 4$ & +4 & +4 & +4 & +4 & +4 & $100 \%$ \\
\hline 13$)(+12):(+4)$ & +3 & +3 & +3 & +3 & +3 & $100 \%$ \\
\hline 14$) 36: 4$ & +9 & +9 & +9 & +9 & +9 & $100 \%$ \\
\hline 15$)(+25):(+5)$ & +5 & +5 & +5 & +5 & +5 & $100 \%$ \\
\hline
\end{tabular}

Fonte: Pesquisa de campo/2015.

Já nas questões de divisão com números inteiros de sinais iguais negativos, houve praticamente $100 \%$ de acertos. Os alunos realizaram corretamente a divisão e trabalharam o conceito de oposto, obtendo êxito nas respostas, exceto um aluno na questão 17.

Quadro 04: Respostas dos alunos do $7^{\circ}$ ano da atividade de divisão com sinais iguais e negativos

\begin{tabular}{|l|c|c|c|c|c|c|}
\hline & \multicolumn{7}{|c|}{ RESPOSTAS DOS ALUNOS } \\
\hline QUESTÕES & ALUNO I & ALUNO N & ALUNO O & ALUNO S & ALUNO T & ACERTOS (\%) \\
\hline 16) (-6) : (-2) & +3 & +3 & +3 & +3 & +3 & $100 \%$ \\
\hline 17) (-10) : (-2) & +5 & +7 & +5 & +5 & +5 & $80 \%$ \\
\hline 18$)(-15):(-5)$ & +3 & +3 & +3 & +3 & +3 & $100 \%$ \\
\hline 19) (-18) : (-2) & +9 & +9 & +9 & +9 & +9 & $100 \%$ \\
\hline 20) (-21) : (-7) & +3 & +3 & +3 & +3 & +3 & $100 \%$ \\
\hline
\end{tabular}

Fonte: Pesquisa de campo/2015.

Em nossas análises, observamos que os alunos sentiram dificuldades inicias no que se referia ao sinal do resultado, mas, ao observarem a semelhança dos sinais nas questões, chegaram às respostas corretas. A priori não esperávamos que os alunos sentissem dificuldades para calcular as operações, justamente por terem o material manipulável como apoio. Porém esse fato não interferiu significativamente no processo, pois houve pouquíssimas respostas incorretas.

Com relação à atividade "Multiplicação e divisão com sinais diferentes”, os alunos logo perceberam que se deveria colocar o sinal (-) nos resultados, pois observaram que as questões eram de sinais diferentes. Tal conclusão feita pelos alunos pode ser consequência da observação feita na atividade sobre a "Multiplicação e divisão com sinais iguais”, na qual os alunos colocaram sinal (+) no resultado.

Os alunos apresentaram dificuldades somente com relação à operação de divisão dos números inteiros e não com relação ao jogo de sinais que deveria ser feito. A seguir apresentaremos os índices de erros dos alunos nas questões de divisão com sinais diferentes. 
Quadro 05: Erros dos alunos do $7^{\circ}$ ano na atividade de divisão com sinais diferentes

\begin{tabular}{|l|c|}
\hline \multicolumn{1}{|c|}{ QUESTÕES } & ERROS (\%) \\
\hline 11) $(+2):(-2)$ & $40 \%$ \\
\hline 12) $10:(-5)$ & $40 \%$ \\
\hline 13) $14:(-7)$ & $20 \%$ \\
\hline 14) $(+15):(-5)$ & $20 \%$ \\
\hline 15) $20:(-4)$ & $20 \%$ \\
\hline 18) $(-14): 2$ & $20 \%$ \\
\hline 19) $(-16):(+4)$ & $20 \%$ \\
\hline 20) $(-20):(+2)$ & $20 \%$ \\
\hline
\end{tabular}

Fonte: Pesquisa de campo/2015.

Finalizando a terceira sessão, foi desenvolvido o jogo "Dama da multiplicação e divisão”. Ressaltamos que o uso de jogos em sala de aula, se utilizado adequadamente, pode contribuir na aprendizagem. Grando destaca:

Muitas vezes os educadores tentam utilizar jogos em sala de aula sem, no entanto, entender como dar encaminhamento ao trabalho, depois do jogo em si. Também, nem sempre dispõem de subsídios que os auxiliem a explorar as possibilidades dos jogos e avaliar os efeitos dos mesmos em relação ao processo ensino-aprendizagem da Matemática. A grande maioria ainda vem desenvolvendo as atividades com jogos espontaneamente, isto é, com um fim em si mesmo, "o jogo pelo jogo”, ou imaginando privilegiar o caráter apenas motivacional. Nota-se uma certa ausência de preocupação em se estabelecer algum tipo de reflexão, registro, formalização ou sistematização das estruturas matemáticas subjacentes à ação no jogo (análise). (GRANDO, 2000, p. 5)

Nesse sentido, buscando amenizar as dificuldades iniciais, realizamos a leitura das regras do jogo com os alunos e exemplificamos com algumas jogadas demonstrativas como eles poderiam proceder. Observamos que nossas estratégias obtiveram resultados bastante positivos, pois os alunos compreenderam a dinâmica do jogo e não apresentaram dificuldades com relação às regras para sua execução.

Os alunos demonstraram ter gostado do jogo e se dedicaram na atividade. Podemos afirmar que o dinamismo criado com o jogo oportunizou aos alunos o desenvolvimento do raciocínio lógico, do diálogo entre os integrantes dos grupos, contribuindo para a assimilação do conteúdo de forma prática, reafirmando a importância que uma atividade diferenciada e bem discutida pode trazer para a compreensão das operações com números inteiros, conforme Meister (2009) destacou em sua pesquisa.

No desenvolvimento desta sessão, os alunos gostaram bastante das atividades com o uso do material manipulável “Quadrados coloridos" e do jogo e da forma que estavam aprendendo. A figura 02, abaixo, ilustra exemplos sobre a visão dos alunos com relação à metodologia adotada.

Figura 02: Opinião dos alunos

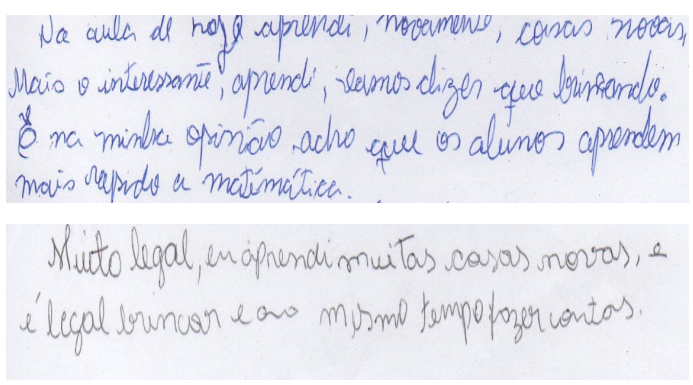

Fonte: Pesquisa de campo/2015.

Na penúltima sessão, desenvolvemos o “Jogo do Dominó”, com o objetivo era sistematizar as regras operacionais envolvendo as operações de adição, subtração, multiplicação e divisão com números inteiros, colaborando para o desenvolvimento por parte dos discentes, do conteúdo trabalhado em sala de 
aula envolvendo as operações com números inteiros.

No “Jogo do dominó”, os alunos puderam assimilar rapidamente as regras adaptadas para trabalharmos as operações com números inteiros, pois dominavam as regras do jogo de dominó tradicional. A situação didática ofertada propiciou condições favoráveis aos pesquisadores no sentido de promover o ensino e a aprendizagem, deixando -a envolvente para o aluno.

Verificamos que, em todo o processo, os alunos sentiram dificuldades para resolver as operações, principalmente as relacionadas ao conceito de oposto, apesar de esse tópico ter sido abordado no decorrer da experimentação com o uso das fichas de atividades e jogos. Em razão das dificuldades que surgiram, houve a oportunidade de os alunos modificarem os esquemas de conhecimento já internalizados previamente, processo importante para a construção do saber.

Ressaltamos, no entanto, que o uso do jogo “dominó” teve sua contribuição para o aprendizado dos alunos, e as dificuldades encontradas no desenvolvimento do jogo não foram um empecilho para que pudéssemos atingir os objetivos desta atividade.

Aúltima sessão teve como objetivo verificar o aprendizado dos alunos após nossa sequência didática através do pós-teste. A seguir apresentamos o desempenho quantitativo de cada aluno quando submetido à sequência didática e que realizaram o pré-teste e pósteste, respectivamente.
Gráfico 01: Acertos dos alunos no pré e pós-teste

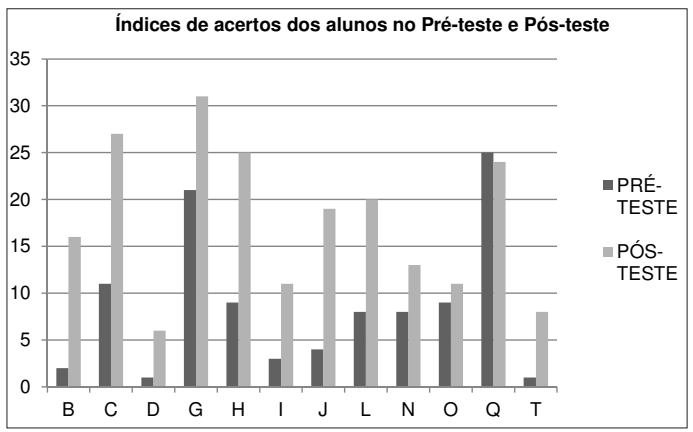

Fonte: Pesquisa de campo/2015.

Na análise sobre os dados apresentados, constatou-se, na comparação dos resultados obtidos, que houve uma considerável melhora no que diz respeito ao aprendizado dos alunos após o desenvolvimento da sequência didática com o uso de material manipulável e jogos, ficando evidente o desempenho individual dos discentes, ainda que o aluno $\mathbf{Q}$ tenha apresentado um pequeno decréscimo. Assim, pode-se concluir que, de modo geral, todos conseguiram apreender conhecimentos sobre as operações básicas com números inteiros, sendo que alguns conseguiram apreender melhor o conteúdo das atividades desenvolvidas em sala de aula e, como destaca Pais (2011) quando trata sobre os conflitos do conhecimento, cada sujeito tem seu próprio ritmo de aprendizagem.

Além disso, é válido destacar que para o bom êxito em atividades como esta é importante atentar também para o papel de cada agente envolvido, isto é, o professor, o aluno e o conhecimento matemático, considerados na compreensão de Brousseau de triângulo didático.

Em Didática da Matemática o professor é responsável por organizar situações didáticas em que nem tudo fica explícito (considerado obstáculos) e também dar a cada aluno meios para que ele avance na construção do 
saber e que possa acessar esse saber nos diversos momentos em que necessite utilizá-lo. O papel do aluno é pensar em possíveis caminhos para resolver os problemas propostos pelo professor, formulando variadas hipóteses, simulando situações, construindo modelos, linguagens, conceitos, etc.; já o conhecimento pode ser determinado por uma situação, entendida como uma ação entre duas ou mais pessoas, que pode ser articulado de acordo com as necessidades cognitivas do sujeito (BROUSSEAU, 1986).

Constatamos também que a intervenção de ensino contribuiu consideravelmente para o processo de ensino e aprendizagem do conteúdo trabalhado, com o desenvolvimento de habilidades e competências, como a capacidade de observação, de proposição, diálogo, autonomia e autoconfiança.

Portanto, o uso de jogos e materiais manipuláveis como ferramentas metodológicas, devidamente planejadas e estruturadas pelo professor, contribui significativamente para a construção da aprendizagem de modo mais eficiente e permanente, contrariando os defensores do uso de metodologias unicamente tradicionais para o ensino de matemática.

\section{Considerações finais}

Para desenvolvimento desta pesquisa, tínhamos como objetivo analisar o desempenho de alunos do $7^{\circ}$ ano do Ensino Fundamental quando submetidos a uma sequência didática com o uso de jogos e materiais manipuláveis relacionados ao conteúdo das operações com números inteiros, buscando favorecer o processo de ensino e aprendizagem das regras operacionais. Desta forma, houve a construção e aplicação de atividades com o uso de jogos e materiais manipuláveis que permitiram aos alunos descobrir e enunciar as regras operacionais usadas no cálculo das operações com números inteiros, antes da institucionalização do saber.

Por meio da metodologia adotada, verificamos um envolvimento gradual de todos os alunos durante o processo, os quais demonstraram em alguns momentos iniciais dificuldades com o método, mas, em sequência, se adaptaram e passaram a gostar da estratégia, principalmente pela sua possibilidade de oferecer uma maneira diferenciada de aprender. Os resultados revelaram que a maioria dos alunos teve um melhor desempenho tanto qualitativamente quanto quantitativamente após a sequência de ensino.

Além disso, o ensino com o uso de materiais manipuláveis e jogos mostrou-se como uma eficiente alternativa metodológica para o ensino das operações com números inteiros, podendo ser adotada por docentes que tiverem interesse em metodologias que apresentam um diferencial no modo de trabalhar o referido conteúdo, pois proporciona significativos resultados levando o discente a avançar na construção e compreensão das noções, propriedades, regras e conceitos matemáticos sobre os números inteiros.

Assim, almejamos que este estudo possa contribuir para a prática de professores de matemática que costumam trabalhar com as operações com números inteiros e que os motive a adotar novas metodologias e posturas na sala de aula. Esperamos que essa pesquisa possa influenciar na investigação de novos trabalhos que tenham por finalidade apresentar práticas de ensino para educação matemática.

\section{Referências}
ALVES, E. M. S. A ludicidade e o ensino de matemática: uma prática possível. Campinas: Papirus, 2012. 
BORDIN, L. M. Os materiais manipuláveis e os jogos pedagógicos como facilitadores do processo de ensino e aprendizagem das operações com números inteiros. 2011. Dissertação (Mestrado em Física e Matemática) - Centro Universitário Franciscano de Santa Maria, Santa Maria, 2011.

BRASIL, Ministério da Educação. Parâmetros Curriculares Nacionais para o Ensino Fundamental. $5^{\mathrm{a}}$ à $8^{\mathrm{a}}$ série, Brasília, SEF, 1998.

Secretaria de Educação Fundamental. Parâmetros Curriculares Nacionais: Matemática. Brasília, MEC, SEF,1997.

BROUSSEAU, G. Introdução ao estudo das situações didáticas: conteúdos e métodos de ensino. São Paulo: Ática, 2008.

Fondements et méthodes de la didactique des mathématiques. Recherches em Didactique des Mathématiques, Grenoble, v. 7, n. 2, p. 33-116, 1986.

COLL, C. Aprendizagem escolar e construção do conhecimento. Porto Alegre: Artmed, 1994.

FIORENTINI, D; MIORIM, M. A. Uma reflexão sobre o uso de materiais concretos e jogos no ensino da matemática. Boletim da SBEM, São Paulo, n.7, p. 1-7, julho/agosto, 1990.

GRANDO, R. C. O jogo e suas possibilidades no ensino de matemática. 1995. 194 f. Dissertação (Mestrado em Educação) - Faculdade de Educação da Universidade Estadual de Campinas, 1995.

HILLESHEIM, S. F. Os números inteiros relativos na sala de aula: perspectivas de ensino para a regra de sinais. 2013. Dissertação (Mestrado em Educação Científica e Tecnológica) - Universidade
Federal de Santa Catarina, Florianópolis, 2013.

LIELL, C. C. Jogo roletrando dos inteiros: uma abordagem dos números inteiros na $6^{\mathrm{a}}$ série do ensino fundamental.2012. $158 \mathrm{f}$. Dissertação (Mestrado Profissionalizante em Ensino de Ciências Exatas) - Centro Universitário Univates, Lajeado, 2012.

MARCONI, M. A; LAKATOS, E. M. Técnicas de pesquisa. São Paulo: Atlas, 1991.

MEISTER, J. C. Estudando dificuldades na compreensão de números inteiros. Trabalho de Conclusão de Curso. Porto Alegre, 2009.

MINAYO, M. C. S. O desafio do conhecimento científico: pesquisa qualitativa em saúde. São Paulo: HucitecAbrasco, 1994.

NACARATO, A. M. Eu trabalho primeiro no concreto. Educação Matemática em Revista, RS, v.9, n. 9/10, 2004-2005.

PAIS, L. C. Didática da matemática: uma análise da influência francesa. Belo Horizonte: Autentica, 2011.

POMMER, W. M. Diversas abordagens das regras de sinais nas operações elementares em Z. Seminários de Ensino de Matemática/ SEMA - FEUSP, março 2010. Disponível em: <http://www.nilsonjosemachado.net/ sema20100316.pdf.> Acesso em: 02 nov. 2010

SALGADO, R. C. S. O ensino de números inteiros por meio de atividades com calculadora e jogos. 2011. 272 f. Dissertação (Mestrado em Educação) - Universidade do Estado do Pará, Belém, 2011. 